\title{
CONSIDERAÇÕES ACERCA DAS NORMAS PARA PUBLICAÇÕES CIENTÍFICAS: INOVAÇÕES, DISCORDÂNCIAS, PROBLEMAS E CONCORDÂNCIAS
}

\author{
CONSIDERATIONS ABOUT THE RULES FOR SCIENTIFIC PUB- \\ LICATIONS: INOVATIONS, DESAGREEMENTS, PROBLEMS \\ AND CONCORDANCES
}

Vera Lucia Adami Raposo do AMARAL*

\begin{abstract}
O cenário nacional das publicações científicas tem apontado para algumas mudanças que tendem a adequar as publicações nacionais às tendências internacionais.
\end{abstract}

Estas tendências se observam, principalmente, em uma mudança no que se refere à redução do número de páginas totais para os artigos aceitos para publicação em periódicos, na modalidade pesquisa científica.

Em geral, os periódicos estão fixando em um máximo de 10 páginas o montante adequado para um trabalho científico. Isto tem gerado conseqüências na forma e estilo do material a ser produzido e comunicado. Os autores passaram a reduzir o número de páginas para a introdução e revisão bibliográfica. Há de se considerar, também, que o número de publicações atuais em todas as áreas do conhecimento tem aumentado assustadoramente, gerando um volume tão gran- de de informação, que em um curto espaço de tempo, torna-se quase que impossível de ser absorvido.

Portanto, os autores não tem se expandido muito em suas buscas bibliográficas e parecem tender a referenciar, em seus trabalhos, os que o influenciaram ou se relacionaram diretamente a eles.

Tem-se, assim, um afunilamento e especificação bastante grande da informação. Prioriza-se com isto a explanação detalhada dos objetivos ou hipóteses, do método e da análise de resultados. Isto permite a replicação das pesquisas e a conseqüente validação do dado científico.

Observa-se, tam bém, a red ução do $n$ úme- ro de páginas na discussão, com enfoque obje- tivo nas conclusões obtidas através da investiga- ção. O que parece ser uma tendência internaci- onal é a introdução de discussões do artigo, enserida no periódico, logo após os mesmos, e feita por autores convidados, cuja experiência e notório saber na área, permitem uma leitura crítica e construtiva, onde muitas vezes são focalizados os controles utilizados pelos autores na investigação e mesmo a verificação de "bias" que, no calor de seus trabalhos, muitas vezes, os próprios autores não reconhecem.

Uma alteração comum que tem ocorrido, no texto, é a supressão dos números como indicação da referência bibliográfica, substituin-

(*) Professora do Curso de Pós-Graduação em Psicologia da PUC-Campinas, e Editora Chefe do Periódico "Estudos de Psicologia".

Endereço para correspondência: Rua Alcides de Godoy, 211 - CEP 13095-200 - Campinas-SP- E-mail:vraposo@mpc.com.br 
do-os pelo sobrenome dos autores e datas. Isto facilita o reconhecimento do artigo mencionado, alguns deles clássicos e de outros, que embora recentes, conseguiram muito impacto em sua área.

Outra inovação se refere à exclusão ou diminuição das notas de roda pé e anexo. A maioria dos periódicos já não aceita em suas normas para publicação artigos que contenham notas de rodapé e anexos.

As publicações brasileiras apresentam muitos problemas comuns, e em algumas áreas, como a Psicologia, se fazem sentir de maneira particularmente relevante. O que se observa dentre os periódicos de circulação nacional é complexo e traz inúmeras conseqüências negativas.

O primeiro e maior problema a ser discutido é o não seguimento de uma única norma de publicação. Seja seguindo as normas do Publication Manual (APA, 1994) ou da ABNT (Associação Brasileira de Normas Técnicas, 1989), ou outra norma qualquer a questão se torna mais complexa quando os autores confundem duas ou mais normas, ora fazendo uso de uma, ora fazendo uso de outra. Este fato se evidencia nas dissertações e teses, e torna-se um mau exemplo a serseguido, perpetuando-se assim um erro, que por condescendência ou benevolência de orientadores e membros das bancas examinadoras, parece de somenos importância.

Outro problema que se enfrenta nas publicações nacionais é o não seguimento rigoroso de uma mesma norma. Os periódicos, em geral, em suas normas para publicação, informam que os autores devem enviar seus trabalhos dentro das normas da APA, ou de outra qualquer adota- da pelo periódico. Entretanto, não é raro vermos muitos artigos chegarem para serem editorados com inconsistências, que não são coerentes com nenhuma norma vigente, muitas vezes não passando de uma "inovação" do próprio autor. Isto fica claro não só na forma de referenciação bibliográfica como na criação de verdadeiros neologismos, no texto.

Os autores freqüentemente apresentam uma confusão no uso dos tempos verbais, ora usando o impessoal, o pessoal singular, ou o pessoal no plural. Isto faz com que o estilo do texto fique confuso, as frases mal formuladas, o que gera compreensão dúbia, ou mesmo incorre- ta. Outro problema da utilização inapropriada dos tempos verbais é o uso da voz passiva, levando a compreensão completamente errada do senti- do que o autor quis dar à frase ou ao texto.

As confusões acerca da referenciações bibliog ráficas são inúmeras, embora alg umas de menor importância, apontam para o descaso com que muitas vezes o assunto é tratado. Em alguns periódicos os exemplos para referências bibliográficas vêem de uma forma e são inseridas no texto de outra forma. Às vezes, no exemplo oferecido pelas "Normas para os Autores" o nome do periódico ou do livro vem sublinhado e no texto aparece em itálico. Naturalmente, este problema não se configura em erro, porque, em geral, os manuais que determinam as normas técnicas informam que estes devem ser desta- cados com uma forma gráfica e não especificam se devam ser sublinhado, vir em negrito ou em itálico. Entretanto, esta observação parece rele- vante uma vez que mostra algumas incongruências comuns nas áreas das normas para publicação e sobre o que finalmente, na realidade se está praticando.

O que sublinhar na referências bibliográficas? Muitas vezes se sublinha somente 0 nome da periódico. Nas normas do p. ' lication Manual (APA, 1994) se sublinha também o volume. Outra polêmica observada é o lugar onde é inserida a data da publicação. Cada vez mais os periódicos tendem a uniformizar, colocando a data da publicação logo em seguida ao nome dos autores, e a ordem das referências sendo organizadas alfabeticamente, ao invés de por data, ou outro critério qualquer, que porventura possa seradotado pelo próprio autor.

Atualmente, quase todo periódico científico exige os resumos do artigo em português e em inglês, seguidos concomitantemente das palavras-chaves. Este procedimento é de máxima importância nas indexações e na recuperação da informação. Embora este já seja um procedimento comum entre os periódicos, ainda não é totalmente adotado nas teses e dissertações, deixando para as bibliotecas a tarefa de 
selecionar as palavras-chaves. Os autores assim procedendo estão no mínimo, menosprezando o valor de seu trabalho, porque provavelmente as palavras chaves utilizadas por um não especialista da área poderá trazer um viés grande na recuperação da informação e na seleção do leitor especializado de um determinado tema.

Gostaríamos de apontar algumas referências específicas, que são bastante complexas de serem corretamente indicadas, e foram observadas, nas publicações nacionais na área de Psicologia, como sendo alvo de um maior número de erros. Estas são algumas delas:

- Resumos apresentados em Anais de Congressos como fonte original (Publication Manual, APA, 1994, pp.198199);

- Resumos extraídos de uma fonte secundária (Publication Manual, APA, 1994, pp.199);

- Livros, com Junior no sobrenome (Publication Manual, APA, 1994, pp.201);

- Livro, grupo de autores (agência governamental) como editor (Publication Manual, APA, 1994, pp.201);

- Livro, sem autor ou editor (Publication Manual, APA, 1994, pp.202);

- Livros traduzidos (Pubication Manual, APA, 1994, pp.203);

- Na área da Psicologia, o Diagnostic and Statistical of Mental Disorders (Publication Manual, APA, 1994, pp.202);

- Contribuição não publicada feita em Simpósio (Publication Manual, APA, 1994, pp.211);

- Trabalho apresentado em um Congresso e não publicado (Publication Manual, APA, 1994, pp. 211);

- Tese de Doutorado ou Dissertação de Mestrado não publicadas (Publication Manual, APA, pp. 213);

As indicações bibliográficas entre parênteses informam as páginas do Publication Manual (APA, 1994), onde podem ser encontradas as formas corretas de referenciá-las, uma vez que nas publicações nacionais, na área da Psicolo- gia, ainda são as normas da APA (American Psychological Association) as mais freqüentemente adotadas.

Outra inovação se refere à mídia ele-trônica.

Já existem disponível alguns guias para a citação da informação eletrônica, embora a forma de referenciação não difira muito da forma de referência em papel. Em geral, ela mantém a norma do sobrenome do autor, seguida de vírgula, seguida da data da publicação entre parênteses, ponto, título do artigo, nome do periódico grifado, seguida da informação de que se trata de uma publicação on-line entre parênteses, o volume disponível grifado seguido de dois pontos e a especificação do caminho ou site onde será encontrado o artigo. O mesmo é valido para os resumos on-line.

Outra inovação da mídia eletrônica é a disponibilização dos resumos e artigos em CDROM. Também aqui a forma de referência não é muito diferente do formato em papel, sendo necessária a especificação da fonte.

Concluindo, pode-se notar que este é um momento de grandes modificações e inovações no que se refere às normas para publicações científicas, que devem estar prontas para atender aos desafios de um novo milênio. Sem dúvida, estamos tendo que encarar uma total revolução no mundo das comunicações e das descobertas científicas e tecnológicas. A aceleração da globalização vem tornando o mundo cada vez menor, em um certo sentido, mas cada vez mais complexo, exigindo da humanidade um esforço grande de criatividade para melhorar a qualidade de vida dos seres humanos e colocar cada vez mais a ciência e a tecnologia sob o estandarte do desenvolvi-mento e benefício da humanidade.

\section{REFERÊNCIASBIBLIOGRÁFICAS}

American Psychological Association. (1994)

Publication Manual (4th edition). Washington, DC: Author.

ASSOCIAÇÃO BRASILEIRA DE NORMAS TÉCNICAS(1989), RiodeJaneiro. NB-66: referências bibliográficas. Rio de Janeiro.19p. 